\title{
PATRIMONIO RELIGIOSO UNA LECTURA LEGAL
}

\author{
Juan Pablo de la Puente Brunke*
}

A lo largo de más de dos mil años, el culto, el apostolado y la labor de la Iglesia Católica han catalizado la creatividad del ser humano. La fe se ha venido plasmando en toda clase de objetos que, en la actualidad, son obras de arte, como lo serán en el futuro los que hoy son elaborados. Sin embargo, dichos objetos no son únicamente valiosas obras de arte. Desde una partitura musical barroca, un ornamento litúrgico, hasta una pintura mural o un templo colonial, todos son representaciones culturales del ser humano, de épocas, devociones, estilos y técnicas artísticas, distintas y únicas. Todo bien cultural representa un contenedor de información y conocimiento que nos acerca al pasado y nos permite formar nuestra conciencia de identidad. En el caso de nuestro país, el patrimonio religioso es una evidencia tangible del rol fundamental que la Iglesia Católica ha jugado en la formación de la nación peruana.

La Iglesia Católica es el mayor poseedor y propietario de bienes culturales integrantes del patrimonio cultural de la nación. Ello implica un gran reto $y$ responsabilidad puesto que la ley peruana impone diversas obligaciones a la posesión y al uso de dichos bienes, así como severas sanciones. ¿Qué entiende la ley peruana por patrimonio cultural de la nación? ¿Cómo se formula su protección y cuáles son sus consecuencias prácticas? A continuación nos acercaremos al patrimonio cultural de la nación, y en especial al patrimonio religioso, desde la óptica de la ciencia del Derecho; aprovechando la reciente aprobación de la nueva Ley General del Patrimonio Cultural de la Nación, Ley $\mathrm{N}^{\circ} 28296$.

\section{NATURALEZA DE LOS BIENES CULTURALES QUE INTEGRAN EL PATRIMONIO CULTURAL DE LA NACIÓN}

Cotidianamente mencionamos que los bienes de hasta 20 o 30 años de antigüedad son pasados de moda, los de 70 son viejos y los de más de 100 son antigüedades. ¿Pero cuál de ellos es un bien cultural? ¿Cuáles merecen una protección especial?

En todo bien cultural evidenciamos la yuxtaposición del interés público y del interés privado. El primero justifica el deber del Estado de proteger determinadas manifestaciones culturales relevantes. El segundo viene determinado por la esfera de derechos que el propietario o poseedor ejerce sobre el bien en cuestión. Adicionalmente a la variedad de derechos que podrían concurrir, también hay que precisar que ello implica la concurrencia de diversas personas, cada una como titular de diferentes derechos. Como ejemplo, tomemos el caso de una pintura. Sobre ella pueden concurrir diversos derechos y personas: el autor, el museo, la galería o el propietario. 
Según el jurista español Jesús Prieto de Pedro ${ }^{1}$, en la regulación legal de bienes culturales el término "patrimonio" implica tres conceptos: (i) su origen etimológico (pater) hace referencia a una herencia que se recibe de los antepasados; (ii) destaca que esa unidad conceptual representa intereses jurídicamente relevantes; (iii) agrupa a un conjunto heterogéneo de bienes a efectos de ser protegidos jurídicamente.

Como ya hemos adelantado, la protección legal no responde únicamente a los aspectos físicos de los bienes culturales. Sin duda el valor estético es uno de los predominantes; sin embargo, coexiste además el valor científico. El patrimonio cultural no se reduce a una pieza o un conjunto de piezas, sino -como todo- al entorno de ellas: "... el contexto en el cual funcionó o se explica desde el presente" ${ }^{\prime 2}$. Asimismo, evidenciamos que junto al valor estético y científico también predominan otros valores subjetivos que consolidan, junto a los primeros, la conciencia de identidad nacional. "Los bienes que son expresiones de la cultura no son meras cosas físicas sino una agregación de perspectivas, de valores y de intereses merecedores de protección" ${ }^{\prime 3}$.

Si bien reconocemos en la actualidad que los intereses de protección vienen determinados por la conjunción de diversos valores, la justificación para la protección de los bienes culturales ha evolucionado en los últimos 300 años.

En el siglo XVIII, principalmente debido a la revolución francesa, se inicia el interés científico por la civilización humana. Las obras de arte dejan de ser objetos de deleite estético para comenzar a ser vistos como fuente de conocimiento.

En el siglo XIX, por vez primera se concibe la idea de que los bienes culturales forman la identidad de un pueblo. Sin embargo, ello no estaba reconocido legalmente permitiendo la realización de expediciones de recolección de bienes artísticos a lo largo de todo el mundo.
"Si las búsquedas frenéticas de antigüedades, organizadas en el siglo XIX, en nombre de la ciencia, pueden ser vistas retrospectivamente con cierta severidad por su relativa falta de discernimiento, los perjuicios provocados en nuestros días por saqueos salvajes, practicados de manera cada vez más sistemática (acarreando así una irremediable pérdida de información), deben probablemente considerarse con un sentimiento de pesar y de inquietud aún mucho mayores" 4 .

El siglo XX representa un cambio radical respecto de la regulación legal de protección de bienes culturales reconociéndose, en el ámbito internacional, la relación que los bienes culturales tienen con sus contextos originales. Frente a ello la Unesco cumple un rol normativo, culminando con la polémica entre el nacionalismo y el internacionalismo del siglo XIX. En el siglo XX se formulan tratados internacionales relacionados con el patrimonio cultural, cada uno con temas y ámbitos específicos.

La Convención Unesco de 1954 establece disposiciones para la protección de bienes culturales en caso de conflicto armado. La Convención Unesco de 1970 dispone mecanismos para evitar el tráfico ilícito de bienes culturales; su ámbito de aplicación son los bienes culturales de naturaleza mueble. En cuanto a los bienes inmuebles es la Convención Unesco de 1972 la que determina las medidas básicas para su protección, creando la lista del Patrimonio Mundial y la del Patrimonio Mundial en Peligro. Posteriormente, en el año 2001, se aprueba la Convención Unesco sobre la protección del patrimonio cultural subacuático. Finalmente, en el año 2003, se aprueba la Convención Unesco de protección del patrimonio cultural inmaterial. Además de las Convenciones de la Unesco debemos mencionar al Convenio Unidroit ${ }^{5}$ de 1995 , sobre los bienes culturales robados o exportados ilícitamente.

1 Jesús Prieto de Pedro. Estudios sobre la Constitución española. Homenaje al profesor Eduardo Carcía de Enterria. Madrid, Civitas, 1991, vol. I1, p.1552.

2 Franklin Pease. Prólogo. En Alberto Martorell. Patrimonio cultural. Políticas contra el tráfico ilicito. Lima, Fondo de Cultura Económica, 1998, p.16.

3 Fernando de Trazegnies. "La conservación moderna del patrimonio cultural de la nación". En Patrimonio cultural del Perú. tima, Fondo Editorial del Congreso del Perú, 2000, tomo I, p. 36.

4 Pascal Riviale. Los viajeros franceses en busca del Perú antiguo. Lima, Fondo Editorial de la Pontificia Universidad Católica del Perú, 2000, p. 355.

5 Unidroit (Instituto Internacional para la Unificación del Derecho Privadol. 
En cuanto al ámbito regional contamos con la Convención de San Salvador de 1976 de la Organización de Estados Americanos, y la Decisión 460 de la Comunidad Andina, del año 1999, sobre la protección y recuperación de bienes culturales del patrimonio arqueológico, histórico, etnológico, paleontológico y artístico de la Comunidad Andina.

Adicionalmente a las normas internacionales mencionadas - por cierto las de la OEA y de la Comunidad Andina se centran en ámbitos regionales; la Unión Europea por su parte ya ha emanado diversa legislación al respecto-, cabe precisar que el interés de la Iglesia por sus bienes culturales ha devenido en la formulación de diversos documentos. En efecto, a través de la Pontificia Comisión de Bienes Culturales de la Iglesia, el Santo Padre ha dictado diversos principios y lineamientos que demuestran la preocupación y la responsabilidad que la Iglesia reconoce tener frente a sus bienes culturales.

Entre la documentación mencionada, debemos hacer referencia a las siguientes Cartas Vaticanas: (i) "Formación de los futuros presbíteros en el cuidado de los bienes culturales de la Iglesia", de fecha 15 de octubre de 1992; (ii) "Las bibliotecas eclesiásticas en la misión de la Iglesia", de fecha 19 de marzo de 1994; (iii) "La función pastoral de los archivos eclesiásticos", de fecha 2 de febrero de 1997; (iv) "Carta circular sobre la necesidad y urgencia de inventariar y catalogar los bienes culturales de la iglesia", de fecha 8 de diciembre de 1999; y (v) "Carta circular sobre la función pastoral de los museos eclesiásticos", de fecha 15 de agosto de $2001^{6}$.

Así en la actualidad el concepto de bien cultural ha sido ampliado, especialmente por la labor legislativa de la Unesco. Nuevas categorías han sido incorporadas, como el patrimonio cultural subacuático y el patrimonio cultural inmaterial. Por ello podemos definir como "bienes culturales" a cualquier manifestación material o inmaterial del ser humano, como individuo o como grupo social.

\section{PROTECCIÓN LEGAL DEL PATRIMONIO CULTURAL DE LA NACIÓN}

Si bien todas las manifestaciones culturales, en sentido lato, constituyen bienes culturales, no todos ellos integran el patrimonio cultural de la nación. Es decir, en cuanto a la relación existente entre bienes culturales y los bienes culturales integrantes del patrimonio cultural de la nación, los primeros lo son por su propia naturaleza, los segundos por opción del legislador y por decisión de la administración pública.

La figura del patrimonio cultural no pretende, ni debe hacerlo, tener como objetivo la protección de todos los bienes culturales. Por razones prácticas, seria imposible e ineficiente tender un manto de protección sobre todos ellos. Su naturaleza se fundamenta en preservar, proteger, fomentar y difundir elementos o manifestaciones culturales propias, definidoras y esenciales de una nación.

Por estas razones $y$ tomando en cuenta que la ciencia del Derecho es una útil herramienta de control y cambio social, el ordenamiento jurídico introduce la categoría de patrimonio cultural como una regulación para preservar características esenciales de una nación.

En nuestro ordenamiento, de conformidad con el artículo $21^{\circ}$ de la Constitución de $1993^{7}$, el patrimonio cultural de la nación está compuesto por los yacimientos y restos arqueológicos, construcciones, monumentos, lugares, documentos bibliográficos y de archivo, objetos artísticos y testimonios de valor histórico, expresamente declarados bienes culturales, y provisionalmente los que se presumen como tales, independientemente de su condición de propiedad privada o pública.

6 El texto completo de los mencionados documentos se encuentra en la siguiente página web: www.vatican.va/roman_curia/pontifical_commissions/pcchcindex_sp.htm

7 "Articulo $21^{\circ}$.- Patrimonio Cultural de la Nación

Los yacimientos y restos arqueológicos, construcciones, monumentos, lugares, documentos bibliográficos y de archivo, objetos antísticos y testimonios de valor histórico, expresamente declarados bienes culturales, y provisionalmente los que se presumen como tales, son palrimonio cultural de la Nacion, independientemente de su condicion de propiedad privada o pública. Están protegidos por el Estado. La ley garantiza la propiedad de dicho patrimonio. Fomenta conforme a ley, la participación privada en la conservación, restauración, exhibición y difusión del mismo, asi como su restitución al pais cuando hubiere sido ilegalmente trasladado fuera del territorio nacional". 
Este precepto constitucional, norma de mayor jerarquía en nuestro ordenamiento respecto del patrimonio cultural, reconoce dos principios fundamentales. En primer lugar, el patrimonio cultural está compuesto por los bienes culturales expresamente declarados como tales y por los bienes culturales que se presume integrantes del patrimonio cultural. En segundo lugar, los bienes del patrimonio cultural pueden ser de propiedad privada o de propiedad estatal.

En la misma línea, la nueva Ley General del Patrimonio Cultural de la Nación, Ley $\mathrm{N}^{\circ} 28296$, recientemente aprobada y publicada el 22 de julio de 2004, define al patrimonio cultural de la nación respetando los principios constitucionales mencionados ${ }^{8}$. De esta manera, uno de los ejes fundamentales de la protección legal del patrimonio cultural peruano viene determinado por la declaración expresa y la presunción legal.

\section{Declaración expresa}

La declaración es un acto administrativo, emitido de oficio o a solicitud de parte por la autoridad competente, y fruto de un procedimiento, mediante el cual se declara a un bien, material o inmaterial, como integrante del patrimonio cultural de la nación.

Sin embargo, la existencia de la declaración expresa es ampliamente discutida por un nutrido sector de la doctrina nacional. Mientras que para María Rostworowski, Walter Alva y Alberto Martorell, la existencia de la declaración expresa atenta contra el propio patrimonio cultural, especialmente el arqueológico; podemos encontrar que Fernando de Trazegnies, Augusto
Álvarez Calderón ${ }^{9}$ y Fernán Altuve-Febres ${ }^{10}$ reconocen la necesidad jurídica y práctica de la existencia de tal figura.

La etnohistoriadora María Rostworowski opina que la Ley 24047 "... ha expuesto a los monumentos arqueológicos a la depredación y a la destrucción, al exigir que deben ser declarados como tales para que sean protegidos por el Estado"11. Para el arqueólogo Walter Alva: "Nos preocupa la declaración previa o la presunción que muchas veces en los tribunales se convierte en una ambigüedad jurídica que favorece a quienes saquean $y$ destruyen nuestro patrimonio"12. Mientras Martorell sostiene que: "La exigencia de declaración previa para que un bien tenga la condición legal de bien cultural, es un grave error (...) una norma no da la condición de cultural a un bien, sino reconoce en él tal condición"13.

Frente a dichos comentarios cabe mencionar lo siguiente. La figura jurídica de la declaración expresa no es un capricho sin sentido del legislador peruano pues tiene antecedentes en la legislación internacional. En efecto, el artículo $1^{\circ}$ de la Convención Unesco de 1970 define como bienes culturales a "... los objetos que, por razones religiosas o profanas, hayan sido expresamente designados por cada Estado como de importancia..."14.

Asimismo, la figura de la declaración expresa, más allá de ser una opción legislativa, se configura, en términos de la Convención Unesco de 1970, como una obligación del Estado. En efecto, dicha convención establece como obligación de cada Estado Parte, el "establecer y mantener al día a partir de un Inventario

8 "Artículo II.- Definición

Se entiende por bien integrante del Patrimonio Cultural de la Nación toda manifestación del quehacer humano -material o inmaterial- que por su importancia, valor y significado paleontológico, arqueológico, arquitectónico, histórico, artístico, militar, social, antropológico, tradicional, religioso, etnológico, científico, tecnológico o intelectual, sea expresamente declarado como tal o sobre el que exista la presunción legal de serlo. Dichos bienes tienen la condición de propiedad pública o privada con las limitaciones que establece la presente Ley".

9 Augusto Álvarez Calderón. "La Ley Ceneral del Patrimonio Cultural de la Nación. Una visión de conjunto". En Patrimonio cultural del Perú. Lima, Fondo Editorial del Congreso del Perú, 2000, tomo II, pp. 590-597.

10 Fernán Altuve-Febres. "Aproximación a una reforma legal del patrimonio cultural de la nación". En Patrimonio cultural del Perú. Lima, Fondo Editorial del Congreso del Perú, 2000, tomo II, pp. 554-555.

11 Maria Rostworowski. "Patrimonio cultural: Crisis y futuro". En Patrimonio cultural del Perú. Lima, Fondo Editorial del Congreso del Perú, 2000 , tomo I, p. 115.

12 Walter Alva. "Problemática y puesta en valor del patrimonio arqueológico peruano". En Patrimonio cultural del Perú. Lima, Fondo Editorial del Congreso del Perú, 2000, tomo I, p. 127.

13 Martorell, op. cit., p. 76

14 Es sumamente importante hacer notar un error existente en la publicación titulada "El patrimonio cultural en sus textos", compilación de nomas editada en mayo de 1996, con ocasión del Encuentro Nacional sobre Conservación. Protección y Defensa del Patrimonio Cultural. El mencionado error consiste en haber reproducido de manera incompleta el articulo $1^{\circ}$ de la Convención Unesco de 1970 , omitiendo justamente el extremo referido a que cada Estado Parte deberá designar expresamente cuáles bienes culturales considera relevantes y por ello decide proteger. Esta omisión también es subrayada por Ramón Mujica, en sus "Comentarios". En Patrimonio cultural del Perú. Lima, Fondo Editorial del Congreso del Perú, 2000, tomo I, p. 219. 
Nacional de Protección, la Lista de Bienes Culturales Importantes, públicos y privados..." 15 .

En cuanto al derecho comparado, en la Ley del Patrimonio Histórico Español ${ }^{16}$ encontramos que "Los bienes más relevantes del Patrimonio Histórico Español deberán ser inventariados o declarados de interés cultural...". Asimismo, la norma bajo comentario dedica enteramente el Título I al tema de la declaración de Bienes de Interés Cultural; mientras que su Reglamento ${ }^{17}$ dedica enteramente el Capítulo | del Título II "Instrumentos Normativos", al mismo tema.

En el caso de México, la Ley Federal sobre Monumentos y Zonas Arqueológicas, Artísticos e Históricos ${ }^{18}$ establece expresamente que: "Son monumentos arqueológicos, artísticos, históricos y zonas de monumentos los determinados expresamente en esta Ley y los declarados como tales, de oficio o a petición de parte". Mientras que su Reglamento ${ }^{19}$ desarrolla en su artículo $9^{\circ}$, entre otros temas, que las declaratorias, en caso de bienes arqueológicos, deberán contener las características de los bienes materia de ellas así como las limitaciones que generan, además de la obligación de su publicación.

Por otro lado, en cuanto a la legislación de la República Popular China, la Ley de Protección de Reliquias Culturales ${ }^{20}$ recoge la figura de la declaración expresa. En efecto, en el artículo que hace referencia al listado de bienes, tras enumerarlos, establece lo siguiente: "(...) The criteria and measures for the verification of cultural relics shall be formulated by the state department for cultural administration, which shall report them to the State Council for approval (..."n21.
Este dispositivo legal demuestra la existencia de un procedimiento para verificar si un bien podría considerarse como una reliquia cultural (y así ser protegido por las disposiciones de la propia norma). Dicha verificación deberá realizarse dentro del marco establecido por los criterios y medidas aprobadas para ello por el Consejo del Estado, a solicitud de la formulación elaborada por el Departamento Estatal de Administración Cultural.

En cuanto al ordenamiento peruano, la figura de la declaración expresa está contemplada tanto en el ámbito constitucional como en el legal. Cabe mencionar que, adicionalmente, las disposiciones de la Convención Unesco de 1970 forman parte del derecho nacional, de conformidad con nuestra Constitución.

El primer antecedente normativo nacional que contempla la declaración expresa es el Reglamento de la Ley del Patrimonio Documental de la Nación ${ }^{22}$ de 1975. Según lo dispuesto en esta norma, para que los documentos privados integren el patrimonio documental de la nación se requiere, previa evaluación, que el Archivo General de la Nación los declare como tales. Asimismo, la figura de la declaración formal ya estaba contemplada en nuestra Constitución de $1979^{23}$.

Es fundamental resaltar que la calidad de bien cultural responde a su esencia y no a la declaración formal. En efecto, la declaración no define a un bien cultural como tal, importa como instrumento para que un bien cultural integre el patrimonio cultural de la nación, es decir para que se le aplique un régimen especial de protección, de naturaleza excepcional.

\footnotetext{
15 Literal b) del anticulo $5^{\circ}$ de la Convención Unesco 1970.

16 Numeral 3) del artículo $1^{\circ}$ de la Ley 16/1985, Ley del Patrimonio Histórico Español, de fecha 25 de junio de 1985.

17 Aprobado mediante Real Decreto 11:/1986, de fecha 10 de enero de 1986

18 Artículo $5^{\circ}$ de la Ley Federal sobre Monumentos y Zonas Arqueológicas, Antísticos e Históricos, publicada en el Diario Oficial de la Federación el 6 de mayo de 1972.

19 Publicado en el Diario Oficial de la Federación el 8 de diciembre de 1975, modificado por Decreto publicado el 5 de enero de 1993.

20 Law of the People's Republic of China on the Protection of Cultural Relics, adoptada en la XXV Reunión del Comité del Quinto Congreso Nacional del Pueblo y promulgada por la Orden $\mathrm{N}^{\circ} 11$ del Comité del Congreso Nacional del Pueblo y vigente desde el 19 de noviembre de 1982.

21 Penúltimo párrafo del artículo $2^{\circ}$.

22 Aprobado mediante Decreto Supremo $\mathrm{N}^{\circ}$ 022-75-ED.

23 "Articulo $36^{\circ}$.- Los yacimientos y restos arqueológicos, construcciones, monumentos, objetos artísticos y testimonios de valor histórico, declarados Patrimonio Cultural de la Nación, están bajo el amparo del Estado. La ley regula su conservación, restauración, mantenimiento y restitución".
} 
La función de la declaración es delimitar expresamente cuáles bienes culturales son regulados de manera especial. De esta manera una persona, sea privada o pública, conocerá indubitablemente cómo deberá comportarse frente a cuáles bienes. Además de restricciones, la declaración expresa importa como vehículo para otorgar beneficios, como los tributarios.

Para De Trazegnies ${ }^{24}$, la figura de la declaración expresa se justifica pues al Derecho no le bastan las consideraciones filosóficas sobra la naturaleza trascendental del patrimonio cultural. El sistema jurídico requiere de una definición operativa. Esta es la única manera para que una regulación sea aplicable de manera eficiente. Las buenas intenciones pueden quedarse solo en esa condición o transformarse en atropellos de derechos constitucionalmente reconocidos.

La declaración expresa de un bien como integrante del patrimonio cultural genera la aplicación de un régimen exorbitante de protección que se traduce en la limitación del ejercicio de los derechos de particulares sobre los bienes materia de tal protección. Por ello cabe tomar en cuenta un aspecto esencial relacionado con la declaración expresa: el procedimiento de formulación, que debe garantizar una adecuada evaluación de las razones por las cuales la autoridad competente pretende declarar un determinado bien. Asimismo, debe permitir la participación de los titulares de derechos que se verían afectados por la declaración.

La participación del titular (o titulares) de derechos en el procedimiento administrativo es esencial y responde al ejercicio mismo de estos. La administración pública no puede limitar dicho ejercicio sin la defensa de sus titulares. En algunos casos la limitación de los derechos es de tal magnitud que en la práctica implica su desnaturalización. Coloquialmente podríamos decir que estamos frente a una suerte de "expropiación" sin justiprecio y sin proceso judicial.
En el ordenamiento peruano, la declaración no emana de un procedimiento administrativo como tal. No hay participación de interesados ni de instituciones reconocidas. La sola decisión de los organismos competentes, fruto de una evaluación interna, no pública, basta para la emisión de la declaración expresa, con la consecuente limitación de derechos.

En cambio, en el ordenamiento español sí se contempla la declaración como conclusión de un procedimiento administrativo. No solo con la participación de los titulares de derechos con legítimo interés, pues es necesaria la evaluación previa de instituciones reconocidas en el ámbito cultural, independientes de la autoridad competente. En efecto, la Ley del Patrimonio Histórico Español, Ley 16/1985, publicada el 29 de junio de 1985 , establece expresamente en el artículo $9^{\circ}$ que:

"... 2. La declaración mediante Real Decreto requerirá la previa incoación y tramitación de expediente administrativo por el Organismo competente (...) en el expediente deberá constar informe favorable de alguna de las Instituciones consultivas señaladas en el artículo $3 .^{\circ}$, párrafo $2 .^{\circ 25}(\ldots)$ Cuando el expediente se refiera a bienes inmuebles se dispondrá, además, la apertura de un período de información pública y se dará audiencia al Ayuntamiento interesado (...)".

Cabe rescatar otro aporte de la norma mencionada. El instrumento normativo mediante el cual se hace la declaración es un Real Decreto. Esta norma es de mayor jerarquía a la emitida por un máximo funcionario de la autoridad competente donde se tramita el procedimiento administrativo.

En la misma línea, el segundo párrafo del artículo $12^{\circ}$ del Real Decreto $111 / 1986$, dispone que:

“... 2. La incoación se notificará a los interesados cuando se refiera a expedientes sobre bienes muebles. Monumentos y jardines históricos $y$,

24 Trazegnies, op. cit, p. 50

25 Las instituciones consultivas son, de acuerdo a la norma, las Reales Academias, las Universidades Españolas, el Consejo Superior de Investigaciones Cientificas, entre otras instituciones. 
en todo caso, al Ayuntamiento del municipio en cuyo término éstos radiquen si se trata de inmuebles. La incoación se publicará también en el Boletín Oficial del Estado, sin perjuicio de su eficacia desde la notificación, y se comunicará al Registro General de Bienes de Interés Cultural para su anotación preventiva (...)".

Estas disposiciones españolas desarrollan claramente el principio de publicidad del procedimiento administrativo para la declaración expresa. Sin embargo, para evitar que el conocimiento público se utilice en contra de la integridad misma de los bienes, el primer párrafo del artículo $11^{\circ}$ de la Ley del Patrimonio Histórico Español, Ley 16/1985, dispone que "1. La incoación de expediente para la declaración de un Bien de Interés Cultural determinará, con relación al bien afectado, la aplicación provisional del mismo régimen de protección previsto para los bienes declarados de interés cultural". La experiencia española es ejemplar. Protege su patrimonio cultural a través de procedimientos enmarcados dentro del principio del respeto a los derechos de las personas.

En cuanto al procedimiento peruano de declaración no existe la publicidad, ni la participación de los interesados, ni la independencia del actuar de la autoridad competente. No existe ningún control sobre ella, en cuanto a la declaración expresa se refiere. Desgraciadamente, la nueva ley peruana $N^{\circ} 28296$ no contempla la existencia del Consejo del Patrimonio Cultural, incorporado por el artículo $9^{\circ}$ de la Ley $\mathrm{N}^{\circ}$ 24047 derogada. De acuerdo a su formulación, el mencionado Consejo ejercía la función de segunda instancia administrativa. Es decir, podía revisar y revocar las decisiones del Instituto $\mathrm{Na}$ cional de Cultura, del Archivo Nacional y de la Biblioteca Nacional.

Finalmente, luego de estas consideraciones surge una natural crítica. ¿Qué sucederá con los bienes culturales no declarados (o no conocidos)? ¿El requisito de la declaración expresa implica entonces una mayor desprotección del patrimonio cultural? ¿Sus detractores tienen la razón? La respuesta es no.
La solución que nos brinda el Derecho es la figura de la presunción de bien integrante del patrimonio cultural de la nación, que a continuación desarrollaremos.

\section{Presunción de bien integrante del patrimonio cultural de la nación}

Como vimos en el punto anterior, la figura de la declaración expresa y previa como requisito para que un bien sea considerado como patrimonio cultural de la nación es la forma jurídica más adecuada para aplicar una regulación de protección de bienes culturales. No constituye únicamente una obligación del Estado derivada de la Convención Unesco de 1970, sino que protege el interés público y evita vulnerar derechos constitucionales de particulares. Sin embargo, pudimos evidenciar el talón de Aquiles de la declaración expresa: no protege a los bienes no declarados. Como solución, el Derecho nos brinda la figura de la presunción. El ordenamiento peruano de protección del patrimonio cultural es pionero al contemplar expresamente la figura de la presunción. Ninguna otra legislación, tanto internacional como comparada, utiliza expresamente la presunción como figura jurídica para proteger el patrimonio cultural. Ninguna Constitución del mundo la contempla. En nuestro país, tanto la Constitución de 1993 como la nueva Ley $\mathrm{N}^{\circ} 28296$, así como la derogada 24047 , la contemplan expresamente.

En virtud de la presunción, los bienes culturales no declarados expresamente se reputan como declarados, siempre y cuando sus características, a simple vista, sean similares a las consideradas por el ordenamiento para integrar el patrimonio cultural. Es decir, "... todo lo que parezca huaco es huaco, mientras no se pruebe lo contrario" 26 .

En virtud de la presunción se invierte la carga de la prueba. Es decir, el Estado puede aplicar el régimen de protección sobre un bien sin necesidad de probar que dicho bien cuenta con una declaración expresa o que sus características sean relevantes para que sea considerado y declarado como patrimonio cultural. Sin embargo, como es posible que el bien sea una réplica o 
una falsificación o una artesanía, se permite la prueba en contrario. Es decir, un turista puede certificar que lo que se está llevando a su país es una artesanía y no una pieza prehispánica.

Sin embargo, la efectividad de la presunción se ha visto maniatada. Desde que fue introducida por la Ley $N^{\circ} 24047$ en 1985, sus principios de protección no han podido ser aplicados pues la mencionada ley nunca fue reglamentada. Así, en la actualidad, los beneficios de protección que implica su existencia no pueden ser aplicados por ningún juez o fiscal. Para ellos es fundamental tener una declaración expresa. Debemos reconocer que existe grave responsabilidad en los funcionarios competentes pues a lo largo de 19 años (desde que se publicó la Ley $N^{\circ} 24047$ ) no existió la voluntad de reglamentar la aplicación práctica de la presunción. Si bien se discute o se alaba, la presunción nunca se ha usado porque jamás se ha reglamentado ${ }^{27}$.

El reconocimiento legal de la figura de la presunción para proteger el patrimonio cultural de la nación responde además a consideraciones prácticas. Sería físicamente imposible declarar como culturales todos los bienes existentes en nuestro país, aunque el Estado disponga de los recursos necesarios, tomando en cuenta además la riqueza cultural y ancestral de nuestro país. De esta manera se evidencia el fundamental papel de la presunción como coadyuvador del deber del Estado de amparar y proteger al patrimonio cultural de la nación.

El reconocimiento constitucional de la presunción constituye un gran avance en el ordenamiento de protección del patrimonio cultural. De conformidad con la Constitución de $1979^{28}$, únicamente los bienes declarados expresamente gozaban de protección del Estado. En cambio, la Constitución de $1993^{29}$ amplía la protección a los bienes aún no declarados expresamente como patrimonio cultural, a través de la presunción.
El primer antecedente normativo nacional que recoge expresamente la presunción es el Reglamento de la Ley del Patrimonio Documental de la Nación ${ }^{30}$ de 1975. Si bien esta norma se refiere únicamente a una clase de bienes culturales, es interesante tomar nota de su aporte:

"Artículo 1.- El Patrimonio Documental de la Nación está constituido por:

Documentos y expedientes existentes en los Archivos de las reparticiones y organismos del Sector Público Nacional y en los archivos históricos, notariales, eclesiásticos y parroquiales; y Documentos y expedientes existentes en los archivos particulares y cualquier material documental de origen privado que sinva de fuente de información para estudios históricos y sobre el desarrollo cultural, social, económico y jurídico del país.

Artículo 2.- Los documentos y expedientes referidos en el inciso a) del artículo anterior integran el Patrimonio Documental de la Nación sin necesidad de calificación expresa.

Para que los documentos y expedientes referidos en el inciso b) del artículo anterior integren el Patrimonio Documental de la Nación se requiere que, previa evaluación, sean declarados parte integrante del mismo por el Archivo General de la Nación, órgano de ejecución del Instituto Nacional de Cultura. Se presume que estos documentos y expedientes integran el Patrimonio Documental de la Nación, salvo declaración expresa del Archivo General de la Nación, cuando tienen una antigüedad de cien años o más".

Como ya hemos mencionado, si bien el ordenamiento peruano es pionero al recoger expresamente la figura de la presunción de bienes culturales, tanto a escala constitucional como legal, en la legislación comparada podemos encontrar la aplicación práctica de su espíritu.

\footnotetext{
27 Luis laime Castillo. "Comentarios" en Patrimonio cultural del Perú. Lima, Fondo Editorial del Congreso del Perú, 2000, tomo 1, p. 214.

$28 \mathrm{Cr}$. Nola 23.

29 "Antculo $21^{\circ}$ - Los yacimientos y restos arqueológicos, construcciones, monumentos, lugares, documentos bibliográficos y de archivo, objetos artísticos y testimonios de valor histórico, expresamente declarados bienes culturales, y provisionalmente los que se presumen como tales, son patrimonio cultural de la Nación, independientemente de su condición de propiedad privada o pública. Están protegidos por el Estado (...)".

30 Aprobado mediante Decreto Supremo $\mathrm{N}^{\circ} 022-75-\mathrm{EO}$
} 
En la experiencia española, si bien no encontramos la figura de la presunción de bienes culturales de forma expresa, pudimos ubicar la aplicación práctica de su razonamiento, en un sentido más estricto. El numeral $1^{\circ}$ del artículo $11^{\circ}$ de la Ley 16/1985, Ley del Patrimonio Histórico Espanol, establece expresamente: "La incoación de expediente para la declaración de un Bien de Interés Cultural determinará, con relación al bien afectado, la aplicación provisional del mismo régimen de protección previsto para los bienes declarados de interés cultural".

Como viéramos en el punto anterior, esta norma regula el procedimiento administrativo de declaración de un bien de interés cultural. El razonamiento práctico de la presunción peruana es utilizado, a grandes rasgos, claro está: se aplica un régimen especial de protección a algo que aún no se determina si cumple con los requisitos para ello. Es una manifestación ingeniosa de protección.

La aplicación de la figura de la presunción tiene razón de ser por la existencia del requisito de la declaración expresa de bienes culturales integrantes del patrimonio cultural de la nación. Por ello, en la doctrina nacional, los detractores y defensores de la presunción son los mismos respecto de la figura de la declaración expresa y previa.

Para el ex congresista Fernán Altuve-Febres, la presunción de bien cultural "... constituye un extraordinario perímetro protector que permite al Estado salvaguardar el interés común y al particular desarrollarse con la seguridad jurídica de una propiedad no mediatizada, que además puede ser responsablemente supervigilada para casos de deterioro" 31 . La ex congresista María Ofelia Cerro Moral, haciendo referencia al artículo $2^{\circ}$ de la Convención Unesco de 1972, así como a la Convención de San Salvador, critica la existencia de la presunción al sostener: "¿Cómo entendemos entonces que el artículo $2^{\circ}$ de la ley 24047 'presuma' que son bienes culturales aquellos que convenciones supranacionales, de las que somos signatarios, han declarado de manera directa?" 32 . Este argumento también lo comparte Alberto Martorell, "... estas convenciones determinan y establecen con carácter de ley; no presumen" ${ }^{\prime 3}$.

Lo que Cerro Moral y Martorell no han advertido es el ámbito de aplicación de los convenios internacionales. Si bien dichos instrumentos son parte del derecho nacional al haber sido suscritos por el Perú, no pueden determinar cuáles bienes son patrimonio cultural del Perú. El listado de objetos de las mencionadas convenciones internacionales citado (así como lo recogido por la Convención Unesco de $1970^{34}$ ) es una forma operativa del derecho para que los Estados Parte puedan implementarla. La lista de objetos de dichas convenciones no es una declaración sino una guía para que los Estados Parte puedan aplicar las medidas de protección.

\section{CONSECUENCIAS DE LA DECLARACIÓN (Y DE LA PRESUNCIÓN)}

Antes de ingresar a comentar los aportes y novedades de la nueva Ley $\mathrm{N}^{\circ} 28296$, es oportuno definir algunos principios para la aplicación del sistema de protección del patrimonio cultural de la nación. En el plano teórico, toda declaración debe traer consigo las siguientes consecuencias:

- Reconocimiento del bien en cuestión como elemento esencial de la cultura y de la identidad nacional.

- La declaración debe redundar en beneficio del bien materia de la declaración.

En un sentido estrictamente jurídico, el régimen legal de protección no se aplica a los bienes del patrimonio cultural. Los bienes son objetos inanimados; por ello, en estricto, las normas del régimen excepcional de protección se aplican a

3) Altuve-Febres, op. cit., p. 550.

32 Marla Olelia Cerro Moral. "Patrimonio cultural: Proyectos de ley y legislación nacional e internacional". En Patrimonio cultural del Perú. Lima, fondo Editorial del Congreso del Perú, 2000, tomo II, p. 541.

33 Mantorell, op. cit., p. 77.

34 El aniculo $1^{\circ}$ de la Convención Unesco de 1970 define al patrimonio cultural como el designado expresamente como bal por cada Estado Parte. Sin embargo, esta convención es omitida en el análisis de la ex congresista Cerro Moral. 
las diversas relaciones jurídicas y a las situaciones jurídicas de las personas (sean naturales o jurídicas, de derecho público como de derecho privado, nacionales como extranjeras). Es decir, las normas de protección se aplican al comportamiento de los individuos, no a los bienes.

Tomemos como ejemplo los objetos arqueológicos que aún no han sido descubiertos. ¿Dichos bienes se encuentran protegidos? En un sentido lato podríamos decir que sí. Sin embargo, supongamos que una cerámica moche continúe enterrada por toda la eternidad. ¿Acaso el derecho se aplica en algún momento? El régimen exorbitante de protección del patrimonio cultural aparece en escena cuando una persona entra en contacto con dichos bienes y pretende realizar actos que la legislación prohíbe.

Lo expuesto determina que el legislador, antes de establecer las medidas de protección, deba evaluar las consecuencias que generan en el comportamiento humano. Es decir, las disposiciones legales deben estructurarse de tal forma que incentiven comportamientos acordes con el objetivo de protección.

Es fundamental que la regulación no desnaturalice los derechos de las personas cuyo objeto sean los bienes declarados. Es decir, para que la protección redunde en beneficio del patrimonio, debe beneficiar igualmente a la persona titular de derechos sobre el mismo. Ello debe implicar un plus para el propietario. Esta regla debe ser la general.

De esta manera, el respeto por los derechos de los particulares no es eficaz únicamente por el hecho de ser reconocidos por nuestra Constitución. Las disposiciones de protección del patrimonio cultural de la nación deben articularse tomando en cuenta dichos derechos, con el objetivo de incentivar comportamientos acordes con la protección y no con la destrucción. Es decir, debe ser más barato cumplir que incumplir la ley.

\section{Diversos niveles de protección: Principio de gradualidad}

La declaración de un bien como patrimonio cultural de la nación no debe traer consigo siempre las mismas consecuencias. Estas deben venir determinadas tanto por la naturaleza y relevancia de las características del bien materia de la declaración como por el objetivo de la protección.

La existencia de diferentes niveles de protección implica necesariamente una declaración expresa previa. Sin un estudio e individualización de cada bien sería físicamente imposible identificar la magnitud e importancia de sus valores culturales para determinar qué nivel de protección le corresponde o requiere.

Este principio de gradualidad de las consecuencias sí es recogido por la legislación comparada. En cuanto a la experiencia española, la Ley 16/1985, Ley del Patrimonio Histórico Español, también contempla distintos niveles de protección. El numeral 3 del artículo $1^{\circ}$ establece que "Los bienes más relevantes del Patrimonio Histórico Español deberán ser inventariados o declarados de interés cultural en los términos previstos en esta Ley". Asimismo, el numeral 1 del artículo $9{ }^{\circ}$ dispone que "Gozarán de singular protección y tutela los bienes integrantes del Patrimonio Histórico Español declarados de interés cultural por ministerio de esta Ley o mediante Real Decreto de forma individualizada (...)".

En el caso de la República Popular China, por ejemplo, el primer párrafo del artículo $7^{\circ}$ de la Ley de Protección de Reliquias Culturales ${ }^{35}$ establece lo siguiente:

"Cultural relics, such as sites related to revolutionary history, memorial buildings, sites of ancient culture, ancient tombs, ancient architectural structures, cave temples, stone carvings, etc., shall be designated as sites to be protected for their historical and cultural value at different levels according to their historical, artistic or scientific value (...)". 
Este artículo contempla expresamente el principio de gradualidad. El régimen de protección no es el mismo pues establece la existencia de diferentes niveles de protección, según los valores históricos, artísticos o científicos de cada bien. Esto evidencia un sistema dinámico muy diferente al de nuestro país.

En la experiencia peruana, lo que denominamos y comentamos como principio de gradualidad es omitido por la legislación y es necesario que se implemente. Los efectos jurídicos de la declaración deben de ser variables, es decir, la intensidad y la exigencia de las obligaciones y prohibiciones deben establecerse en función de la relevancia cultural de sus características, así como por el objetivo público de protección.

\section{Consecuencias de la declaración tomando en} cuenta la naturaleza multidimensional de los bienes culturales

Como ya hemos adelantado, la figura jurídica del patrimonio cultural de la nación genera la yuxtaposición de distintas titularidades e intereses respecto de los bienes que lo integran; unas de ámbito público y otras de ámbito privado. Todas ellas deben conjugarse armónicamente. No es únicamente cuestión del respeto a los derechos legítimos sino, más bien, de ello depende el éxito de la protección.

Es necesario tomar en cuenta ciertos aspectos. La declaración legal (y la presunción) mediante la cual se integra al patrimonio cultural de la nación un bien en particular agrupa dos actos: reconoce y protege. Reconoce la importancia cultural por sus características relevantes. Por su parte, la protección y conservación de las características originales o esenciales del bien es la consecuencia de la declaración. Esto implica la limitación de diversos derechos, así como el establecimiento de determinadas obligaciones. Recordemos que la protección se materializa en la regulación de las conductas de personas que se relacionan (en sentido general) con dichos tipos de bienes.

Lo expuesto evidencia la coexistencia de dos ámbitos: el público y el privado. La principal manifestación del ámbito público es el justificado deber del Estado de proteger, conservar, fomentar y difundir el patrimonio cultural de la nación a través de una regulación excepcional y especial.

El ámbito privado está compuesto por los titulares de derechos cuyos objetos son los mencionados bienes. Los bienes pueden ser propiedad de individuos o de colectividades como la Iglesia Católica y comunidades campesinas y nativas. Sin embargo, el ámbito privado no se limita al caso del derecho de propiedad sobre bienes del patrimonio cultural de la nación. Los derechos que pueden coexistir dependen de las características de cada bien. Las distintas dimensiones del ámbito privado no vienen determinadas únicamente por la presencia de diferentes individuos, sino también por la multiplicidad de derechos que pueden coexistir en función a la naturaleza del bien. Recordemos el ejemplo de la pintura.

El patrimonio religioso y las exigencias de la nueva Ley General del Patrimonio Cultural de la Nación, Ley $N^{\circ} 28296$

Como decíamos, con fecha 22 de julio del presente año fue publicada la nueva Ley General del Patrimonio Cultural de la Nación, Ley $\mathrm{N}^{\circ}$ 28296, derogando por completo la antigua Ley $N^{\circ}$ 24027. En esencia, la nueva ley establece nuevas y mayores obligaciones para los privados, así como sanciones.

Para efectos del cumplimiento de la ley peruana de protección del patrimonio cultural, la Iglesia Católica es considerada como un privado más ${ }^{36}$. Cabe precisar que, a diferencia de la nueva ley, la 24027 sí reconocía expresamente la naturaleza peculiar de los bienes culturales de la Iglesia.

36 De conformidad con el articulo $8^{\circ}$ de la nueva Ley: "Anticulo $8^{\circ}$ - Bienes de propiedad de la Iglesia.

El bien integrante del Patrimonio Cultural de la Nación de propiedad de la Iglesia Católica, de las congregaciones religiosas o de otras confesiones, tiene la condición de particular y obliga al propietario a su conservación y registro con arreglo a lo dispuesto en la presente Ley". Sin embargo, debemos tomar en cuenta el Concordato entre la Santa Sede y la República del Perú, suscrito el 19 de julio de 1980 y aprobado mediante Decreto Ley $N^{\circ} 23211$. En el mencionado tratado se reconoce que la Iglesia Católica en el Perú es una persona jurídica de carácter público que goza de plena independencia y autonomía, con plena capacidad y libertad para la adquisición y disposición de bienes. 
En efecto, el artículo $15^{\circ}$ de la norma derogada reconocía expresamente que ellos sirven para el culto como finalidad prioritaria ${ }^{37}$.

Asimismo, cabe preciar que el término "patrimonio religioso" no se encuentra regulado en la ley como categoría especial. Tampoco existen efectos jurídicos especiales. Es decir, el patrimonio religioso es parte del patrimonio cultural de la nación, de la misma manera como podría serlo algún objeto antiguo perteneciente a cualquier ciudadano.

Sin embargo, como ya hemos adelantado, los bienes del patrimonio religioso gozan de una naturaleza distinta a los demás bienes culturales. A continuación citaremos, por su acierto y precisión, la Declaración de El Escorial ${ }^{38}$ respecto de la definición de "Patrimonio Cultural de la Iglesia":

"Patrimonio Cultural de la Iglesia

1. Llamamos 'Patrimonio Cultural de la Iglesia' a los bienes culturales que la Iglesia creó, recibió, conservó y sigue utilizando para el culto, la evangelización y la difusión de la cultura. Son testimonio y prueba de la fe de un pueblo. Son, también, creaciones artísticas, huellas históricas, manifestaciones de cultura y civilización.

2. Este patrimonio nace y se hace para el culto $y$ la evangelización. Este su fin primario y propio es, también, su primer fin social.

3. Los lugares $y$ edificios destinados al culto $y$ reunión de los creyentes, a lo largo de casi veinte siglos y para actos y comunidades variadísimas, han dado origen a su Patrimonio Inmueble, arquitectónico-monumental; los numerosos objetos para el culto y la catequesis, como retablos, pinturas, esculturas, tejidos, orfebrería, etc., forman su Patrimonio Mueble; los manuscritos, libros y documentos que recogen y reflejan la vida del Pueblo de
Dios -su memoria escrita- constituyen su Patrimonio Documental. Todos ellos son huella e instrumento de evangelización" ${ }^{\prime \prime}$.

La Iglesia Católica en el Perú, al igual que en España, constituye el primer sujeto regulado por la normativa que protege el patrimonio cultural. Por ello, a continuación analizaremos las principales novedades de la nueva ley peruana, que involucran al patrimonio religioso:

(i) Toda transferencia de propiedad de bienes muebles o inmuebles integrantes del patrimonio cultural de la nación, entre particulares, deberá ser puesta en conocimiento previo de la autoridad competente. De conformidad con el numeral 9.2 del artículo $9^{\circ}$ de la nueva Ley, el incumplimiento sanciona la nulidad de la transferencia.

(ii) El Estado tiene derecho de preferencia en toda transferencia onerosa de propiedad (mueble o inmueble) de bienes integrantes del patrimonio cultural de la nación. De conformidad con el numeral 9.4 del artículo $9^{\circ}$ de la nueva Ley, el incumplimiento sanciona la nulidad de la transferencia.

(iii)Todo traslado de bien mueble integrante del patrimonio cultural de la nación, dentro del territorio nacional, debe ser puesto de conocimiento previo de la autoridad competente, así como su destino, bajo responsabilidad; de conformidad con el numeral 32.2 del artículo $32^{\circ}$ de la nueva Ley.

(iv)Todo propietario de bienes muebles e inmuebles integrantes del patrimonio cultural de la nación se encuentra obligado a "facilitar" el ingreso de funcionarios competentes, así como de investigadores acreditados, además de brindarles información sobre los bienes, de conformidad con el artículo 21 de la nueva Ley.

\footnotetext{
37 "Arículo 15.- Los bienes culturales de propiedad de la Iglesia y de las congregaciones religiosas sirven para el culto como finalidad prioritaria, sin perjuicio de su carácter de bienes culturales, que obligan a sus propietarios a conservarlos adecuadamente. El Estado garantiza dicha propiedad y asegura su conservación mediante conve nios de asistencia técnica y de cobertura de riesgos en el caso de exhibiciones públicas".

38 Declaración de El Escorial, de fecha 27 de junio de 1996, emitida tras la celebración de las XVI Jornadas Nacionales del Patrimonio Cultural de la Iglesia en Espana, organizadas por la Conferencia Episcopal para el Patrimonio Cultural de la Conferencia Episcopal Española.

39 "Declaración de El Escorial". En Ars Sacra N*1. Madrid, Secretariado Nacional de la Comisión Episcopal para el Patrimonio Cultural de la Iglesia de la Conferencia Episcopal de España, junio 1997, p. 67.
} 
(v) Todo propietario de algún bien (mueble e inmueble) integrante del patrimonio cultural de la nación, deberá solicitar el registro del mismo ante la autoridad competente, de conformidad con el artículo $17^{\circ}$ de la nueva Ley.

Asimismo y respecto de los bienes muebles integrantes del patrimonio cultural de la nación que no se encuentren debidamente inscritos, su propietario deberá solicitar el registro de los mismos ante la autoridad competente, bajo pena de multa; de conformidad con la primera disposición transitoria de la nueva ley.

En la práctica, la obligación de registro implicará que cada uno de nosotros deba solicitar el registro de todas las antigüedades que tengamos en nuestras casas y oficinas, a fin de evitar que seamos multados. Sin duda, para proteger algo es fundamental conocerlo; sin embargo tal como es formulada en la nueva ley, la obligación de registrar generará mayor ocultamiento. Asimismo, el Registro Obligatorio podría fomentar, paradójicamente, mayores saqueos y robos para así acogerse luego a este y justificar su posesión ilícita. El Registro Obligatorio ya fue planteado por vez primera en 1929, mediante la Ley $N^{\circ} 6634$, sin obtener ningún resultado positivo.

Para mejor entender las principales novedades de la ley vigente, antes mencionadas, es conveniente precisar y recordar cuáles bienes son considerados como integrantes del patrimonio cultural. De conformidad con el artículo $21^{\circ}$ de la Constitución de 1993 y los artículos I y II del Título Preliminar de la nueva Ley, el régimen de protección se aplica a los bienes declarados expresamente y a los que se presume como tales.

Asimismo, las autoridades competentes para el derecho peruano son determinadas según el tipo de bien cultural. Si son bienes bibliográficos, le corresponde dicha determinación a la Biblioteca Nacional del Perú; si son bienes archivísticos, le corresponde al Archivo Nacional del Perú. El Instituto Nacional de Cultura es la autoridad competente respecto de los bienes inmuebles y de los bienes muebles distintos a los bibliográficos y archivísticos.

Otro aspecto que debemos tomar en cuenta es que si bien el patrimonio religioso pertenece a la Iglesia Católica, la responsabilidad del cumplimiento de las restricciones y obligaciones de la nueva ley recae en las correspondientes diócesis, archidiócesis, órdenes o cualquier otra persona de Derecho Canónico que, de acuerdo con el Derecho Civil peruano, sea considerada como titular de los bienes culturales.

De otro lado, la nueva Ley $N^{\circ} 28296$ tiene tres aspectos positivos relevantes, en especial respecto del patrimonio religioso. En primer lugar, reconoce expresamente la propiedad que la Iglesia Católica ejerce sobre sus bienes culturales ${ }^{40}$.

En segundo lugar, establece expresamente que los bienes culturales serán devueltos a sus legítimos propietarios en caso de que dichos bienes sean incautados cuando se intente su exportación ilícita ${ }^{41}$. Este aporte es doblemente positivo: por un lado reconoce y protege la propiedad privada; por otro incentiva el registro de bienes muebles (lo que permite su mejor protección, estudio y difusión) puesto que el propietario, a fin de poder recuperar los bienes que le fueron robados, deberá acreditar fehacientemente su posesión lícita. En caso de que no pueda hacerlo se verá impedido de recuperarlos y la propiedad de los mismos pasará automáticamente a favor del Estado.

En tercer lugar cabe mencionar un incentivo tributario incorporado por la nueva ley y que beneficia al patrimonio religioso. De conformidad con el artículo $47^{\circ}$, las donaciones efectuadas en favor de bienes culturales de propiedad de entidades sin fines de lucro podrán ser deducidas como gasto para efectos de la determinación del impuesto a la renta. 


\section{CONSIDERACIONES FINALES}

Es grande el reto que persigue la ley peruana del patrimonio cultural de la nación, así como la Iglesia Católica del Perú como mayor propietaria privada de bienes integrantes (y presuntos) del dicho patrimonio. A manera de ilustración, solo en el año 1999 fueron saqueados 350 templos ${ }^{42}$.

Las mayores amenazas al patrimonio religioso peruano vienen determinadas por el tráfico ilícito de bienes culturales, las obras de expansión urbana sin criterio urbanístico, así como el deber de conservación de dichos bienes; labor que implica fuertes sumas de dinero y una adecuada capacitación de los responsables. Adicionalmente, esta debe incluir la gestión y uso de bienes culturales.

Si bien las amenazas mencionadas exigen que el Estado regule de manera eficaz la protección del patrimonio cultural no solo dictando normas adecuadas, sino reestructurando a las autoridades competentes, la Iglesia Católica, así como cualquier particular, debe realizar todos los actos necesarios para proteger los bienes culturales bajo su responsabilidad.

Las Cartas Vaticanas sobre el tema evidencian principalmente el deber de inventariar y catalogar los bienes culturales de la Iglesia. Ello responde no solo al hecho de conocer y poder estudiar los bienes existentes. La principal razón es por protección contra el tráfico ilícito de bienes culturales. Mediante un inventario, catálogo o registro se podrá acreditar que determinado bien cultural robado pertenece a tal o cual templo, convento, etc.

Las labores de inventario, catálogo o registro no deben ser necesariamente costosas y engorrosas. Una simple fotografía con la respectiva descripción de sus características, junto a la certificación notarial respectiva, podría constituir la mejor prueba para solicitar la devolución de un bien robado.

Como primera etapa, la urgencia de un rápido inventario adquiere mayor relevancia por lo regulado en el artículo $10^{\circ}$ (acreditar propiedad lícita) y en la Primera Disposición Transitoria (Registro Obligatorio) de la nueva Ley $N^{\circ} 28296$, ya comentados.

Sin embargo, cumplida la primera etapa, las labores de inventario, registro y catalogación deben ser vehículos de conocimiento. Para ello dichas labores deben ser realizadas por especialistas y con técnicas homogéneas en todo el territorio peruano. Como propuesta, las distintas diócesis, arquidiócesis, órdenes, etc., deberían reconocer a la Comisión Episcopal para los Bienes Culturales de la Iglesia facultades para dictar lineamientos vinculantes respecto a las técnicas de inventario, catalogación y registro, acordes con las Cartas Vaticanas. Respecto a las otras amenazas del patrimonio religioso, distintas al tráfico ilícito, es conveniente y urgente la capacitación de las personas responsables. El uso, la gestión y conservación de bienes culturales no responden únicamente por responsabilidad moral, la ley impone severas sanciones. 